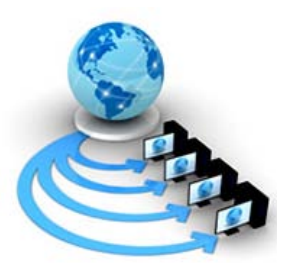

\title{
A LITERATURE SURVEY ON COMPUTING METHODS IN PSYCHIATRIC DISORDER
}

\author{
Shivangi Jain \\ Department of Computer Science and Engineering \\ Bhabha Engineering Research Institute \\ Bhopal, India
}

\author{
Dr. Mohit Gangwar \\ Department of Computer Science and Engineering \\ Bhabha Engineering Research Institute \\ Bhopal, India
}

\begin{abstract}
Data mining algorithms and its application having different and diverse field. One of the challenging and emerging research fields is medical science. Medical field exhibit many type of data and thus it provide large statically and dynamic data, its relevant Meta data which contains a detail information about the observation made in different scenario. Medical data such as EEG, ECG reports, MRI reports, different lab test reports and other observation which are either in text format or graphical image format derived. These are different sample format describe various symptoms and prevention associate with those symptoms. Genetic activity, genes presence and repetition also gives user activity detail and problems in human body. Mental illness is a type of disease which relate with the mental disorder. It deals in human interaction, its behavior, and its regular and irregular activity. In this stage human sudden start misbehave or extra activities during the particular phase and hence an un-predictable incident may occur. Psychiatric disease cases are increasing day by day with different symptoms in human being. These are diseases which occur due to over work pressure, mental activity, some past human life incident or may be the victim of some good or bad incident. It leads to several problems in society, as per well issue with the person who is suffering with the particular disorder. An human interaction and understanding capacity is different than a normal person which keep person separate from the normal society and social life. These disorders also occur sometime very violent and make it very tedious to recover. Psychiatric relate to brain disorder, Mental disorder, irregular work performing in public etc. Diagnosis over the disease is complex and not fixed. In the previous research on the same concern shows that the past data can be analyzed properly and it can further be useful for the precautions. Mental disorder records may leads to several Meta data, report activities observed by hospital or supervision person. A classification over the given symptoms, its action and medical treatment help in diagnosis. Past studies always parts in important role using which further decision can be taken. Mental disorder, mental health, further possibilities can be observed and driven remedy can be discussed. Data classification algorithm makes it possible to classify the normal and abnormal data cases. Hospital release dataset give the information which tends to changes, mental health of previous patients and their best precautions taken to cure them. Different algorithm model is used which help in mining the previous algorithm data rule over the past cases. It enable user to understand past cases, their symptoms, disease occurred and its diagnosis steps taken. Various algorithms such as Genetic algorithm, Naïve bayes, Ant colony optimization, Rule based reasoning (RBR), Case based reasoning (CBR) and Artificial neural network (ANN) is used for psychiatric disease finding from the large dataset. In this paper survey of past techniques is performed. This paper also illustrates the work finding and limitation of previous research. An analysis using the real time dataset over the proposed algorithm is left for further work..
\end{abstract}

Keywords: Data mining, Psychiatric disorder, mental disorder diagnosis, classification technique, ANN approach.

\section{INTRODUCTION}

Now a days Mental disorder and its relevant issues are rising in various segment. People are facing mental disorder due to change in body symptoms. Mood disorder became pretty big issue which works with human nature and deals in various classification algorithm to analyze it [2]. Which is an open research area relate with the data mining approach.

Specific data detection have two approaches to analyze the traffic for incoming data: Misuse approach and Anomaly approach. Misuse detection based follow well defined patterns (or signature) that can usually be detected by doing pattern matching on collected patterns from training data [4].

\section{Psychiatric Disorders}

The mental illness which keeps human in thinking of some illusion unwontedly, it keep human in thinking of data assumption and reacting to that illusion accordingly. Some exceptional thinking and reacting towards lead to psychiatric disorder [14].
The below figure 1 , shows the classification and type of mental disorders which occur in normal human being body occurrence [27].

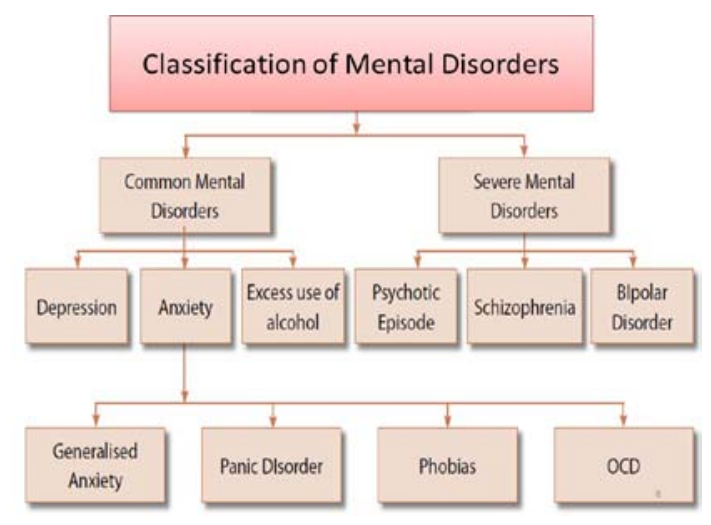

Figure 1: Classification chart of mental disorders diseases A regular checkup and regular monitoring of human nature, body analysis, physical and mood analysis can help in diagnosis and preventing any damage from the disorder. 
This activity help user to sustain and control over the unnatural condition [16].

Following are the disorders come in between:

- Anxiety disorder: People face anxiety by visiting some places or by looking at some people who are unknown to the recognition or different in look or faces $[17,19]$.

- Mood disorders: It includes the feeling which may be sad or happy feeling in unwilling way. Which includes the unwanted movement step which may taken by patient $[17,19]$.

- Psychotic disorders: It is the imagination which comes in people mind such as some image or person who does not having existence [17, 19].

- Eating disorders: It involved in wrong behavior of eating and uncontrolled diet which keep in other disease disorder $[17,19]$.

- Impulse control and addiction disorders: An addiction towards the unwanted thing make it uncontrolled and unhealthy towards wrong saturations $[17,19]$.

- Personality disorders: A physical disorder, physical damage disorder belongs to this category, it may harm person body $[17,19]$.

- Obsessive-compulsive disorder (OCD): It perform user to take obsessive diet and obsessive nature. It may cause germ infection in human [17, 19].

- Post-traumatic stress disorder (PTSD): It make human feel as physically or sexually disable to assault. It keep always in mind of person and afraid of other people to come between [17].

In this paper previous techniques which participated in mental disorder recognition, its understanding level, its treatment program which taken for precaution, its classification algorithm which take participate in data understanding. Clinical service analyses, hospital activity analysis, large number of attributes were observed for data analysis [20]. A comparison analysis table is given which describe the previous technique authors, their techniques, advantage of their research work and limitation of their work. Further an enhancement which can perform for better result is given in our proposed research. Our further study is going to use tool Weka which is build on java API and hence a detail result with graphical analysis can be observed over the obtained dataset from the various provided resources [21].

\section{LITERATURE REVIEW}

In this section different literature survey approach which works towards mining disease parameters towards mental illness and Psychometric diseases using Data mining approaches. This survey define how the different algorithm given and perform for the data detection for diagnosis.

In this paper [1] Author described the work perform by different model to find Interpretation of Neuropsychiatric Diseases. They have performed work with integration of Rule based reasoning (RBR), Case based reasoning (CBR) and Artificial neural network (ANN) which works to find solution on Neuropsychiatric disease. They have worked and showed five neuropsychiatric diseases with 38 symptoms grouped into six categories. Different model for the disease symptom detection is given by them. Feature selection process is performed with ANN along with RBR and CBR approach. The paper described that EEG signal and other resources get generate data periodically.

They have also stated that the combination of EEG parameters, neuroimaging parameters, physiological, psychological and cognitive parameters are required for the detection of neuropsychiatric diseases. Thus it can be determined the disease can be determine using EEG parameters. Paper gives the description of previously performed diseases with psychological analysis. Their model applied to diagnose and analyze them. The work computed by them on weka tool with real time EEG samples gathered from medical research lab and their hybrid approach outperform best with efficient parameter computation. They have stated that CBR approach predicts the order of confidence of disease.

In this paper [3] author worked with genetic algorithm for diagnosis of Alzheimer's disease (AD). They have worked with genetic algorithm steps to determine early stage, middle stage and complex stage of the disease. This disease is related with mental illness which posses different disorder and multiple parameters to compute it. The algorithm works in a process that it first collects all the sample population from the user input dataset. Further it generates the fitness function and finding genome evaluation fitness of each gene. A new population reproduction based on the cross over and mutation technique with the input population. The "best" solution is returned when fitness function reaches target value. The fitness function having function is to evaluate the quality of each proposed solution. The implementation was performed with $\mathrm{C}$ language, also the regression function using $\mathrm{R}$ language. The proposed algorithm by the author outperforms best while comparing existing ROC approach. The proposed algorithm also compared with step wise algorithm. Finally author concluded GA for prediction of $\mathrm{AD}$ progression by combining the results of a large set of neuropsychological measures from the AIBL study that they had been selected for their sensitivity to cognitive impairment in both MCI and AD.

In this paper [5] machine learning algorithm and its usage in finding mental illness is discussed. They have shown the eight different machine learning approach and perform with 5 mental illness problem , 60 sample cases with 25 attribute detection which participate in mental illness is detected over the research. They have used Multilayer Perception, Multiclass Classifier and LAD Tree classified for better efficient results. Main considerable disorder Attention problem, Academic Problem, Anxiety Problem, Attention Deficit Hyperactivity Disorder (ADHD) and Pervasive Developmental Disorder (PDD) taken by the author. In their proposed work first identification of attribute, second feature selection and then finally classification using the machine learning algorithm is performed. The final work performed by them is to determine factor effecting the mental disease. Eight classifier algorithm using Weka tool over Java language is considered, compared with Kappa statistics and ROC curve area values. Result execution shows that Multilayer Perception, Multilayer Classifier and LAD Tree are higher than other classifiers. A further assumption of extending the work is given that a prior training to the classifier can improve the performance of detection technique. 
In this paper [6] Natural language processing and its usage in determining symptoms of mental illness is performed. Their project named Clinical Record Interactive Search Comprehensive Data Extraction (CRIS-CODE) is derived by team to diagnosis of mental illness over the population. Studies from more than 10,000 slips with patient record of 7962 patients with SMI diagnosis and other with same range in non-SMI diagnosis records are taken. Data annotation, detection of natural language processing terms, such as annotation, tagging, pruning and deriving data from large dataset is performed. Their work using the standard hybrid approach of ConText rules and machine learning offered by TextHunter. Which help in tracking different problem and further diagnosis over the data algorithm can be performed. In this paper [7] author discussed about the technique for health diagnosis from the health record generated from the electronic medium such as EEG. Their research were performed on 500,000 diagnoses which is considered population were (recurrent) depression (ICD10 codes F32$33 ; 16.4 \%$ of patients), reaction to severe stress and adjustment disorders (F43; 7.1\%), mental/behavioral disorders due to use of alcohol (F10; 6.9\%), and schizophrenia (F20; 5.6\%). From their research they have also observed, mood (affective) disorders (F31-F39); neurotic, stress-related and somatoform disorders (F40- F48, except F42); and eating disorders (F50) were the diseases found in symptoms. They have stated the top 10 disease symptom cases. Further studies and conclusion made by the research team was if the correct date and data is derived and proceed, it can be very helpful in diagnosis of mental disease detection.
In this paper [10] an Approach which is support vector machine (SVM) is used for the rule classification , feature extraction and optimizing the data processing. They have working with depression and mental illness detection from the MRI samples medical data. The computed work and experiment performed by the author is done with OneR, SVM, and Information Gain (IG) and ReliefF algorithm. Finally following hybrid approach which is SVM Evaluator in combination with Expectation Maximization (EM) classifier and the IG evaluator in combination with Random Tree Classifier have achieved the highest accuracy. Thus the statement is achieved that MRI volumetric features can be useful using the machine learning extraction to detect disease and mental illness disorder. Thus this can further be helpful in diagnosis of mental illness disease in human.

In the same format other researcher they do work with ANN (Artificial neural network) [13] approach and Bayes model for detection of mental depression [9] illness and their diagnosis from the large medical dataset. Data mining approach suits

well and works with high dimension dataset. It can further be finding an advantage of hybrid algorithm and use in performing diagnosis detection. Dataset which is from the real time machine EEG [12] can be collected and further be proceeding for experiment $[23,24]$.

A comparison analysis for the mentioned technique is summarized and marked here in the table below. The following table 1 , discuss about mentioned approaches , advantage, limitation and techniques used previously.

Table 1: Previously performed technique for Psychiatric disorder detection.

This section discuss about detailing related to previous performed approaches, it also summarized previous work [25,26].

\begin{tabular}{|c|c|c|c|c|}
\hline Author & Techniques & Advantage & Disadvantage & Remark \\
\hline $\begin{array}{l}1] \text { Mohit } \\
\text { Gangwar, R. B. } \\
\text { Mishra, R. } \\
\text { Yadav, B. Pandey }\end{array}$ & $\begin{array}{l}\text { Author performed } \\
\text { integration of Rule } \\
\text { based reasoning (RBR), } \\
\text { Case based reasoning } \\
\text { (CBR) and Artificial } \\
\text { neural network (ANN). } \\
\text { A multiple step oriented } \\
\text { technique is involved to } \\
\text { process and } \\
\text { understanding data rule. }\end{array}$ & $\begin{array}{l}\text { All the given } \\
\text { approach is processed } \\
\text { with multiple step } \\
\text { rule generation, data } \\
\text { classification and } \\
\text { ANN algorithm } \\
\text { which help in more } \\
\text { data mobilization. }\end{array}$ & $\begin{array}{lr}\text { A complex } & \text { algorithm } \\
\text { combination } & \text { may } \\
\text { exhibit } & \text { high } \\
\text { computation time to } \\
\text { process large amount of } \\
\text { data. }\end{array}$ & $\begin{array}{l}\text { These techniques are } \\
\text { useful combination . } \\
\text { A combination based } \\
\text { approach can further lead } \\
\text { for effective solution. }\end{array}$ \\
\hline
\end{tabular}




\begin{tabular}{|c|c|c|c|c|}
\hline $\begin{array}{l}\text { Paul Maruff, Greg } \\
\text { Savage , Petra } \\
\text { Graham5, Lance S } \\
\text { Macaulay } \\
\text { Kathryn A Ellis, } \\
\text { Cassandra Szoeke } \\
\text {, Ralph N Martins, } \\
\text { Christopher } \\
\text { Rowe, Colin L } \\
\text { Masters, David } \\
\text { Ames, Ping Zhang }\end{array}$ & $\begin{array}{l}\text { Alzheimer's disease } \\
\text { (AD) prevention and } \\
\text { analysis. } \\
\text { Algorithm keep use of } \\
\text { steps such as crossover, } \\
\text { mutation and fitness } \\
\text { analysis of given data. }\end{array}$ & $\begin{array}{l}\text { because of its steps } \\
\text { involved in } \\
\text { processing the data. } \\
\text { Generic rules can } \\
\text { defined and more } \\
\text { useful for usage. }\end{array}$ & $\begin{array}{l}\text { the data. Any } \\
\text { probability usage in } \\
\text { medical field in } \\
\text { undetermined and } \\
\text { should be avoided. } \\
\text { Hence an optimal value } \\
\text { need to generated. }\end{array}$ & \\
\hline 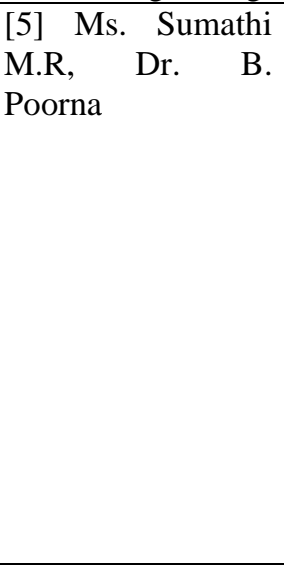 & 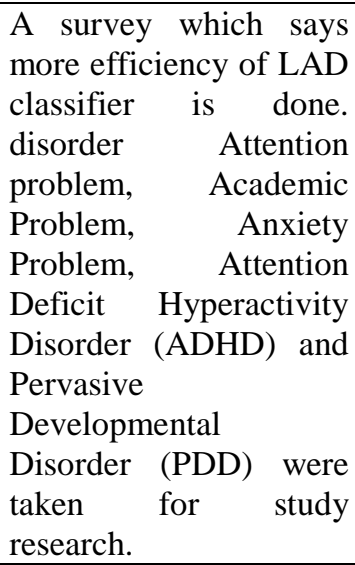 & $\begin{array}{l}\text { A detail analysis of } \\
\text { available } \\
\text { classification } \\
\text { approach is } \\
\text { performed. } \\
\text { Data distribution and } \\
\text { large number of } \\
\text { dataset with attributes } \\
\text { were studied here. }\end{array}$ & $\begin{array}{l}\text { A detail classification } \\
\text { technique, pruning } \\
\text { techniques were not } \\
\text { given. Thus an study } \\
\text { about the pruning is } \\
\text { need to be done for } \\
\text { processing. }\end{array}$ & $\begin{array}{l}\text { Survey of previous } \\
\text { technique is performed. } \\
\text { LAD classifier can be } \\
\text { used in future algorithm. }\end{array}$ \\
\hline $\begin{array}{l}\text { [6] Richard G } \\
\text { Jackson, Rashmi } \\
\text { Patel, Nishamali } \\
\text { Jayatilleke, Anna } \\
\text { Kolliakou, } \\
\text { Michael Ball, } \\
\text { Genevieve Gorrell, } \\
\text { Angus Roberts, } \\
\text { Richard J Dobson, } \\
\text { Robert Stewart }\end{array}$ & $\begin{array}{l}\text { Context rule mining and } \\
\text { natural language } \\
\text { processing is applied to } \\
\text { understand the data. } \\
\text { Clinical } \\
\text { Interactive Record } \\
\text { Comprehensive Dearch } \\
\text { Extraction Data } \\
\text { CODE) project derives } \\
\text { the detail of their work. }\end{array}$ & $\begin{array}{l}\text { An efficient natural } \\
\text { language processing } \\
\text { and understanding } \\
\text { algorithm help user to } \\
\text { create proper set. } \\
\text { Proper usage data } \\
\text { records } \\
\text { examine. }\end{array}$ & $\begin{array}{l}\text { Full length of dataset is } \\
\text { required. Noise removal } \\
\text { before processing data } \\
\text { is need to be executed. }\end{array}$ & $\begin{array}{l}\text { This technique can be a } \\
\text { part of any hybrid } \\
\text { approach for the mental } \\
\text { disorder treatment } \\
\text { analysis algorithm } \\
\text { participate in treatment or } \\
\text { data analysis. }\end{array}$ \\
\hline $\begin{array}{l}\text { [7] Yevgeniya } \\
\text { Kovalchuk1 , } \\
\text { Robert Stewart, } \\
\text { Matthew } \\
\text { Broadbent, Tim J. } \\
\text { P. Hubbard, } \\
\text { Richard J. B. } \\
\text { Dobson }\end{array}$ & $\begin{array}{l}\text { An operational } \\
\text { technique which works } \\
\text { with image EEG format } \\
\text { of data, thus image } \\
\text { feature extraction, } \\
\text { detection technique is } \\
\text { applied over it. }\end{array}$ & $\begin{array}{l}\text { This approach works } \\
\text { with EEG signals, its } \\
\text { analysis which gives } \\
\text { the high amount of } \\
\text { accuracy and real } \\
\text { time user behavior } \\
\text { observation. }\end{array}$ & $\begin{array}{lr}\text { Limited } & \text { to } \\
\text { implementation } & \text { and } \\
\text { data access feature } \\
\text { extraction. } \\
\text { High level of medical } \\
\text { knowledge is required. }\end{array}$ & $\begin{array}{l}\text { This can be a part of } \\
\text { recommendation system } \\
\text { and analysis system to } \\
\text { opt real time accuracy. }\end{array}$ \\
\hline $\begin{array}{l}10] \text { Kipli, } \\
\text { Kuryati, Abbas Z. } \\
\text { Kouzani, and } \\
\text { Isredza Rahmi A. } \\
\text { Hamid }\end{array}$ & $\begin{array}{l}\text { SVM approach is used } \\
\text { for the classification. } \\
\text { Worked towards the } \\
\text { mental illness. They } \\
\text { performed comparison } \\
\text { with OneR, SVM, and } \\
\text { Information Gain (IG) } \\
\text { and ReliefF algorithm. }\end{array}$ & 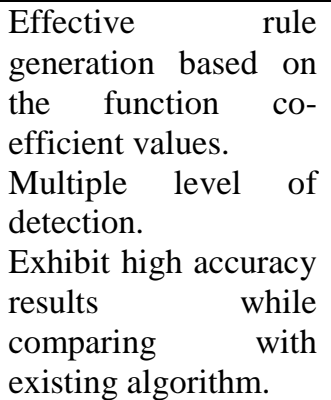 & $\begin{array}{l}\text { Small number of } \\
\text { attributes. } \\
\text { Worked with the low } \\
\text { level of data } \\
\text { transmission. } \\
\text { Rule base generation } \\
\text { but more detail } \\
\text { knowledge can't be } \\
\text { extracted. }\end{array}$ & $\begin{array}{l}\text { This technique can be use } \\
\text { for attribute selection and } \\
\text { feature rule analysis. }\end{array}$ \\
\hline
\end{tabular}

\section{CONCLUSION}

Medical science is an emerging field today. Science with technical approaches deriving new diagnosis and fast way to provide solutions. Different research to understand the disease, to perform work accordingly for diagnosis is derived by technical algorithm. As the paper describe and work towards mental illness and psychology diseases which means by mental disorder and different other mood disorder discussed here. Data mining techniques help in understanding and refining previous raw data. Previously used solution and their diagnosis over the different cases can be utilized. In this paper survey approach over different mechanism is performed. Algorithm such as Genetic algorithm, Bayesian algorithm, Ant colony and other classification approach is discussed here. These are the 
approaches utilized by previous researcher. Thus the analysis shows the previous data can be more useful for diagnosis. Hence an efficient data mining approach is helpful to determine the disease over a patient. Related paper work author also shows the hybrid combination approach to work towards given input dataset. It helps in finding matching data with high accuracy and efficient parameter which comparing with single approach. A further work performing the disease symptom detection with real time dataset over an real time application is left for the future. More parameter and different periodic condition can also be tested in future research.

\section{REFERENCES}

[1]. Mohit Gangwar, R. B. Mishra, R. S. Yadav, B. Pandey, "Intelligent Computing Methods for The Interpretation of Neuropsychiatric Diseases Based on Rbr-Cbr-Ann Integration”, INTERNATIONAL JOURNAL OF COMPUTERS \& TECHNOLOGY Vol 11, No. 5, 2013.

[2]. American Psychiatric Association. "Diagnostic and statistical manual of mental disorders" (5th ed.). Arlington, VA: American Psychiatric Publishing, (2013).

[3]. Piers Johnson, Luke Vandewater, William Wilson, Paul Maruff, Greg Savage , Petra Graham5 , Lance S Macaulay , Kathryn A Ellis, Cassandra Szoeke , Ralph N Martins, Christopher C Rowe, Colin L Masters, David Ames, Ping Zhang, "Genetic algorithm with logistic regression for prediction of progression to Alzheimer's disease”, Johnson et al. BMC Bioinformatics 2014, 15(Suppl 16):S11.

[4]. Francesca Pistollato, Elan L. Ohayon, Ann Lam,” Alzheimer disease research in the 21st century: past and current failures, new perspectives and funding priorities”, Oncotarget, Advance Publications 2016.

[5]. Ms. Sumathi M.R, Dr. B. Poorna, "Prediction of Mental Health Problems Among Children Using Machine Learning Techniques", (IJACSA) International Journal of Advanced Computer Science and Applications, Vol. 7, No. 1, 2016.

[6]. Richard G Jackson, Rashmi Patel, Nishamali Jayatilleke, Anna Kolliakou, Michael Ball, Genevieve Gorrell, Angus Roberts, Richard J Dobson, Robert Stewart," Natural language processing to extract symptoms of severe mental illness from clinical text: the Clinical Record Interactive Search Comprehensive Data Extraction (CRIS-CODE) project”, Jackson RG, et al. BMJ Open 2017;6:e12012. doi:10.1136/bmjopen-2016-012012.

[7]. Yevgeniya Kovalchuk1, Robert Stewart, Matthew Broadbent , Tim J. P. Hubbard, Richard J. B. Dobson,” Analysis of diagnoses extracted from electronic health records in a large mental health case register", PLOS ONE | DOI:10.1371/journal.pone.0171526 February 16, 2017.

[8]. Mohit Gangwar, R. B. Mishra, R. S. Yadav, B. Pandey, "Intelligent Computing Method for the Interpretation of Neuropsychiatric Diseases", International Journal of Computer Applications (0975 - 8887) Volume 55- No.17, October 2012.

[9]. Prentzas, Jim, and Ioannis Hatzilygeroudis. "Categorizing approaches combining rule-based and case- based reasoning." Expert Systems 24.2 (2007): 97-122.

[10].Kipli, Kuryati, Abbas Z. Kouzani, and Isredza Rahmi A. Hamid. "Investigating machine learning techniques for detection of depression using structural MRI volumetric features." International journal of bioscience, biochemistry and bioinformatics 3.5 (2013): 444-448

[11].Marling, Cindy, and Peter Whitehouse. "Case-based reasoning in the care of Alzheimer's disease patients." Casebased reasoning research and development. Springer Berlin Heidelberg, 2001. 702-715.

[12].Sanei, Saeid, and Jonathon A. Chambers. "EEG signal processing." Wiley. com, 2008.

[13].Vollala, Satyanarayana, and Karnakar Gulla. "Automatic Detection of EPILEPSY EEG Using Neural Networks."

[14].Carrillo MC, Sanders CA and Katz RG. Maximizing the Alzheimer's Disease Neuroimaging Initiative II. Alzheimer's \& dementia. 2009; 5:271-275.

[15].M. B. (2005). Clinical utility: A prerequisite for the adoption of a dimensional approach in DSM. Journal of Abnormal Psychology, 114, 560-564. doi:10.1037/0021843X.114.4.560.

[16].Clarke, D. E., Narrow, W. E., Regier, D. A., Kuramoto, S. J., Kupfer, D. J., Kuhl, E. A., . . Kraemer, H. C. (2013). DSM-5 field trials in the United States and Canada, Part I: Study design, sampling strategy, implementation, and analytic approaches. American Journal of Psychiatry, 170, 43-58. doi:10.1176/appi.ajp.2012.12070998.

[17].Krueger, R. F., \& Bezdjian, S. (2009). Enhancing research and treatment of mental disorders with dimensional concepts: Toward DSM-V and ICD-11. World Psychiatry, 8, 3-6.

[18].Insel, T., Cuthbert, B., Garvey, M., Heinssen, R., Pine, D. S., Quinn, K., . . . Wang, P. (2010). Research domain criteria (RDoC): Toward a new classification framework for research on mental disorders. American Journal of Psychiatry, 167, 748-751. doi: 10.1176/appi.ajp.2010.09091379

[19].IBGE (2001) Censo demográ́fico populacional do ano 2000. Instituto Brasileiro de Geografia e Estati'stica Website. Available: http://www.ibge.gov.br/censo/. Accessed 2011 Sept 10 .

[20].Degenhardt L, Chiu WT, Sampson N, Kessler RC, Anthony JC, et al. (2008) Toward a global view of alcohol, tobacco, cannabis, and cocaine use: findings from the WHO World Mental Health Surveys. PLoS Med 5: e141.

[21].Hennigan T (2010) Economic success threatens aspirations of Brazil's public health system. BMJ 341: c5453.

[22]. Mello MF, Kohn R, Mari JdJ, Andrade LH, Almeida-Filho Nd, et al. (2009) The Epidemiology of Mental Disorders in Brazil [La Epidemiologi'a de las Enfermedades Mentales en Brasil]; Rodrı'guez J, Kohn R, Aguilar-Gaxiola S, eds. Washington, DC: Pan American Health Organization. pp 101117.

[23].The World Bank Website. GINI Index.Available: http://data.worldbank.org/ indicator/SI.POV.GINI/. Accessed 2011 Sept 10.

[24].Peen J, Schoevers RA, Beekman AT, Dekker J (2010) The current status of urban-rural differences in psychiatric disorders. Acta Psychiatr Scand 121: 84-93.

[25].Cuthbert, B. N. (2014). The RDoC framework: Facilitating transition from ICD/DSM to dimensional approaches that integrate neuroscience and psychopathology. World Psychiatry, 13, 28-35. doi:10.1002/wps.20087.

[26].American Psychiatric Association. (2015). Structured clinical interview for DSM-5 (SCID-5). Retrieved from http://www. appi.org/products/structured-clinical-interview-for-dsm- 5scid-5.

[27].http://slideplayer.com/slide/9363646/ 